\title{
Long-term complete response of advanced hepatocellular carcinoma treated with multidisciplinary therapy including reduced dose of sorafenib: case report and review of the literature
}

\author{
Masahiro Shinoda', Norihiro Kishida ${ }^{1}$, Osamu Itano ${ }^{1 *}$, Shigenori Ei ${ }^{1}$, Akihisa Ueno ${ }^{2}$, Minoru Kitago ${ }^{1}, Y_{\text {uta }}$ Abe ${ }^{1}$, \\ Taizo Hibi ${ }^{1}$, Hiroshi Yagi ${ }^{1}$, Yohei Masugi ${ }^{3}$, Minoru Tanabe ${ }^{4}$, Koichi Aiura ${ }^{5}$, Michiie Sakamaoto ${ }^{3}$, \\ Akihiro Tanimoto $^{2}$ and Yuko Kitagawa ${ }^{1}$
}

\begin{abstract}
An 83-year-old man underwent computed tomography during a routine check-up due to a history of surgical treatment for pancreatic cancer. Two tumors were detected in the anterior segment of the liver. A needle biopsy of the larger tumor was performed, and pathological examination showed that the tumor was a poorly differentiated hepatocellular carcinoma. Resection was not performed considering the patient's poor physical condition. Thus, transcatheter arterial chemoembolization and radiofrequency ablation of the tumors were performed. Three months later, residual tumor of the larger lesion and multiple pulmonary metastases were detected. This time, continuous hepatic arterial infusion chemotherapy was performed. Although the pulmonary metastases markedly reduced, tumor thrombi appeared in the right portal vein on computed tomography. Finally, sorafenib was administered, which led to disappearance of the tumor thrombi and no other signs of recurrence 8 months after initiation of sorafenib on computed tomography. Although sorafenib administration has continued at reduced doses of $200 \mathrm{mg}$ per day or less due to hypertension, complete response has persisted for the past 34 months. It is noteworthy that sorafenib has been given at reduced doses, but a long-term complete response is maintained in a patient who had portal tumor thrombi and distant metastasis. Herein, we present this rare case of advanced hepatocellular carcinoma controlled with reduced doses of sorafenib following multidisciplinary therapy, describe our single center experience with sorafenib use in patients with hepatocellular carcinoma, and review previous reports that focused on dose reduction of sorafenib.
\end{abstract}

Keywords: Hepatocellular carcinoma, Tumor thrombi, Sorafenib, Reduced dose, Long-term complete response

\section{Background}

Although potentially curative therapies including liver transplantation, resection, and ablations have been developed for hepatocellular carcinoma (HCC), patients with advanced stage of HCC still have poor prognosis [1-3]. The recent development of molecular targeted therapies has begun to change strategies for treating advanced

\footnotetext{
*Correspondence: itano@z8.keio.jp

${ }^{1}$ Department of Surgery, School of Medicine, Keio University, 35

Shinanomachi, Shinjuku-ku, Tokyo 160-8582, Japan

Full list of author information is available at the end of the article
}

HCC. The efficacy and safety of sorafenib for advanced HCC were assessed in the SHARP study [4] and also in the Asia-Pacific study [5]. To date, sorafenib has been applied to a large number of patients worldwide and becomes an important therapeutic option for HCC. A growing number of complete response (CR) patients have been reported since 2008 [6]. Recently, a Japanese multi-center study has reported 18 patients with HCC who achieved $\mathrm{CR}$ after sorafenib treatment and precisely described their characteristics [7]. However, it is still very difficult and extremely rare to maintain $\mathrm{CR}$ for long term in patients with

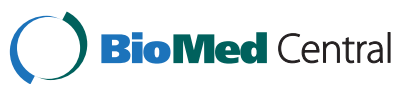

(c) 2015 Shinoda et al.; licensee BioMed Central. This is an Open Access article distributed under the terms of the Creative Commons Attribution License (http://creativecommons.org/licenses/by/4.0), which permits unrestricted use, distribution, and reproduction in any medium, provided the original work is properly credited. The Creative Commons Public Domain Dedication waiver (http://creativecommons.org/publicdomain/zero/1.0/) applies to the data made available in this article, unless otherwise stated. 
advanced HCC. We herein report a case of advanced HCC that was initially treated with multidisciplinary therapy and has maintained a CR status for 34 months using reduced doses of sorafenib. We also describe our singlecenter experience for sorafenib use in patients with HCC and review previous reports that focused on HCC patients with long-term CR using reduced doses of sorafenib.

\section{Case presentation}

An 83-year-old Japanese man underwent distal pancreatectomy for pancreatic body cancer 3 years ago. He had a medical history of hypertension but not of hepatitis virus infection and alcohol abuse. During a postoperative surveillance examination, contrast-enhanced computed
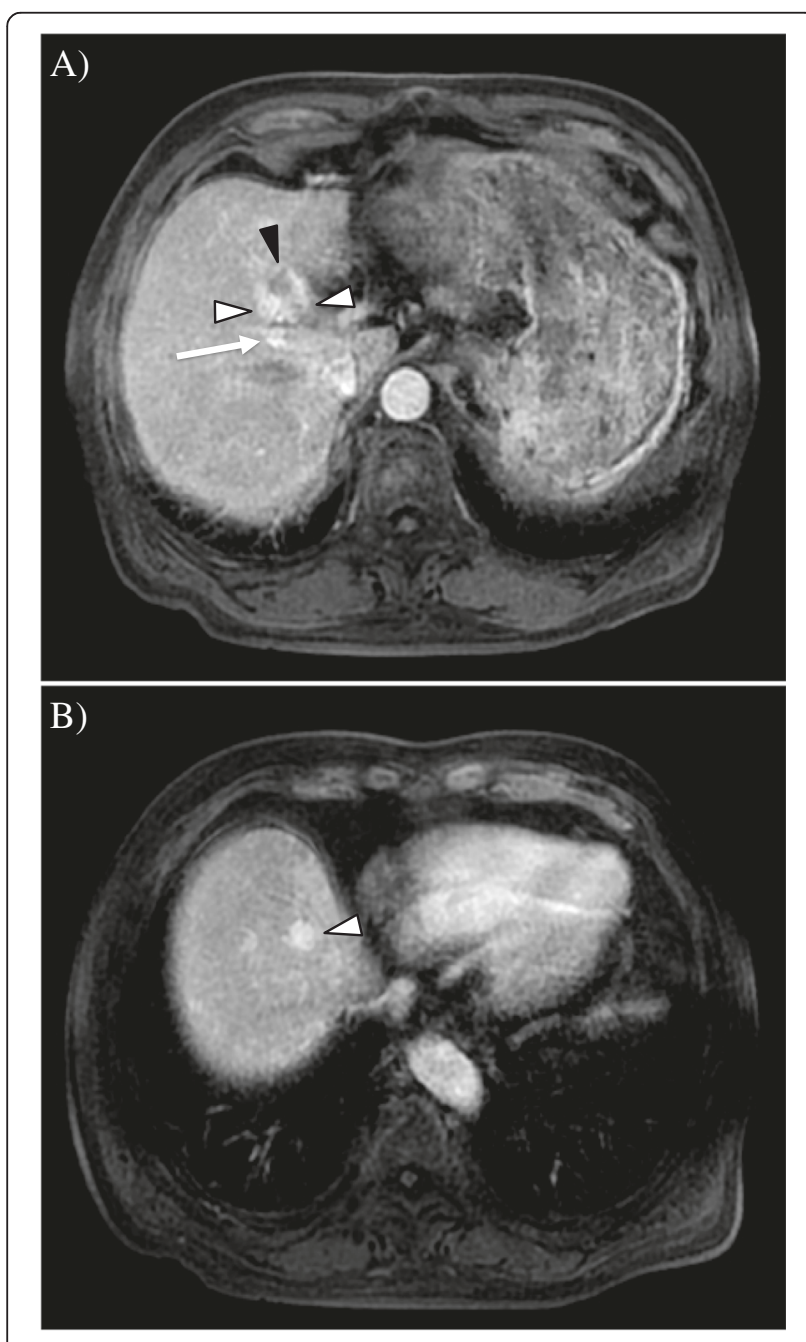

Figure 1 Gadoxetic acid-enhanced magnetic resonance imaging at tumor discovery. Images in the arterial-phase are shown. (A) A large tumor, $23 \mathrm{~mm}$ in diameter, is adjacent to the right Glisson branch (white arrow). The dorsal side of the tumor is hypervascular (early enhancement is indicated by white triangles), and the ventral side is hypovascular (indicated by a black triangle). (B) A smaller tumor, $13 \mathrm{~mm}$ in diameter, is below the right diaphragm. The tumor also shows early enhancement (indicated by a white triangle). tomography (CT) detected two tumors, 23 and $13 \mathrm{~mm}$ in diameter, in the anterior segment of the liver. The larger tumor was adjacent to the right main Glisson branch, and the other lesion was below the right diaphragm. Both of them showed early enhancement in the arterial phase (Figure $1 \mathrm{~A}, \mathrm{~B}$ ) and hypointensity in the hepatobiliary phase in the gadoxetic acid-enhanced magnetic resonance imaging. The patient's serum alpha-fetoprotein (AFP) level was elevated to $8,650 \mathrm{ng} / \mathrm{ml}$ (normal level is less than $20 \mathrm{ng} / \mathrm{ml}$ ). A needle biopsy of the larger tumor was performed, and pathological examination showed that the tumor was a poorly differentiated hepatocellular carcinoma. A specimen from the previously diagnosed pancreatic
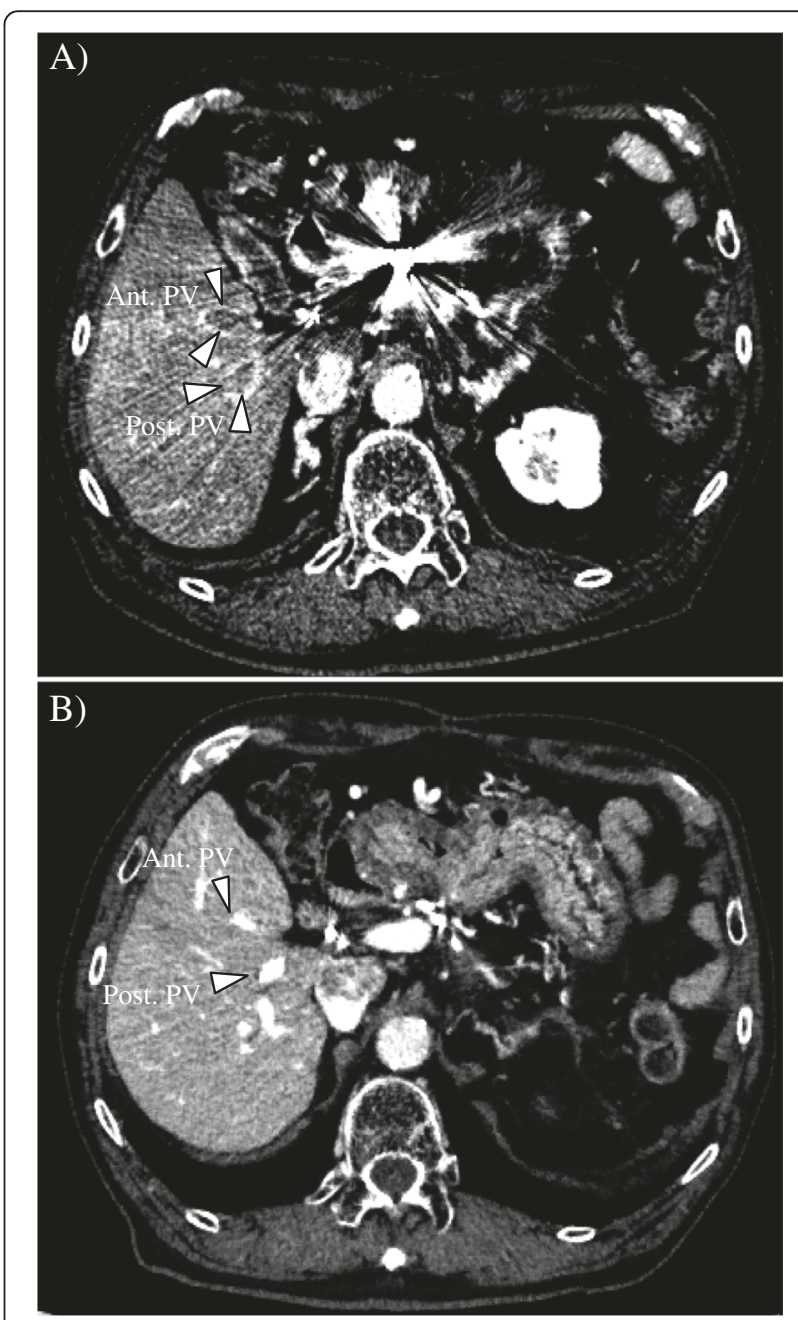

Figure 2 Abdominal contrast-enhanced computed tomography before and after sorafenib introduction. (A) Before sorafenib introduction. Massive filling defects with enhancement are seen in the anterior and posterior branches of the portal vein (indicated by white triangles). An artifact by the catheter and coil placed for hepatic arterial infusion chemotherapy is seen. (B) After sorafenib introduction. The tumor thrombi disappeared in the portal vein (indicated by white triangles). Ant. PV, anterior branch of the portal vein; Post. PV, posterior branch of the portal vein. 
cancer was re-examined, but the finding of ductal adenocarcinoma was identical to the one diagnosed at the time of surgery; and components of hepatoid carcinoma were not found in this specimen. Resection was not performed considering the tumor location (right lobectomy was necessary) and the patient's hepatic functional reserve (ChildPugh classification was grade A, but indocyanine green retention rate at $15 \mathrm{~min}$ was $21 \%$ ) and advanced age. Since the larger tumor was adjacent to the right main Glisson branch and only the bordering side appeared hypervascular, we first performed transcatheter arterial chemoembolization to the hypervascular part of the larger tumor and to the other tumor and then additionally performed radiofrequency ablation of the hypovascular portion of the larger tumor. Three months after the treatment, CT imaging revealed a residual tumor of the larger lesion at the ablation site and multiple lung metastases. Thus, continuous hepatic arterial infusion chemotherapy using 5-fluorouracil and cisplatin was performed for 2 months. This was effective in reducing the residual tumor and lung metastases, but tumor thrombi appeared in the right portal vein (Figure 2A), and his AFP and PIVKA-II levels were elevated to $41,948 \mathrm{ng} / \mathrm{ml}$ and $422 \mathrm{mAU} / \mathrm{mL}$, respectively (Figure 3 ). Subsequently, sorafenib was administered at a reduced dose of $400 \mathrm{mg}$ per day considering his advanced age (the manufacturer's recommended dose is $800 \mathrm{mg}$ per day). The dose of sorafenib was temporarily increased to $800 \mathrm{mg}$ per day but was reduced to $400 \mathrm{mg}$ per day again due to an adverse event of hypertension (grade 3 in Common Terminology Criteria for Adverse Effects version 4.0) (doses are described in Figure 3). Eight months after initiation of sorafenib, his AFP level was decreased to normal level, and both the tumor thrombi in the right portal vein and multiple lung metastases disappeared on CT imaging (Figure 2B). The dose of sorafenib was further reduced to $200 \mathrm{mg}$ per day or $200 \mathrm{mg}$ per 2 days due to hypertension, but there have

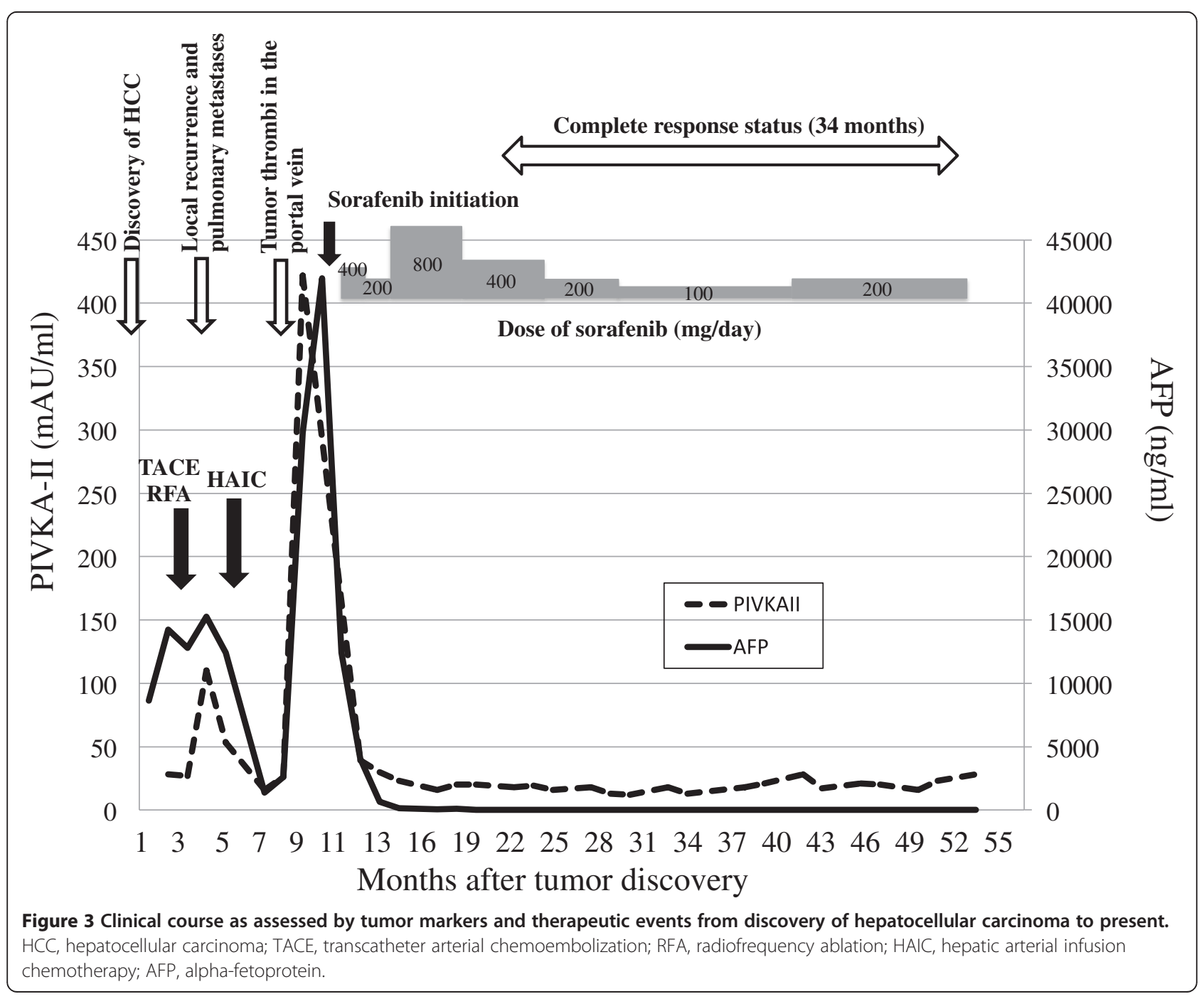


Table 1 Cases who achieved complete response for more than 2 years in the literature

\begin{tabular}{|c|c|c|c|c|c|}
\hline & Case 1 & Case 2 & Case 3 & Case 4 & Present case \\
\hline Reported year [reference] & $2011[8]$ & $2011[8]$ & $2013[9]$ & $2013[10]$ & 2014 \\
\hline Age/sex & 70/male & $69 / \mathrm{male}$ & 71/male & 74/male & 83/male \\
\hline Background liver disease & Hepatitis C & Hepatitis C & Hepatitis C & Hepatitis B & Non-viral, non-alcoholic \\
\hline \multicolumn{6}{|l|}{$\begin{array}{l}\text { Tumor status at sorafenib } \\
\text { initiation }\end{array}$} \\
\hline Number & Single & Not described & Multiple & Single & - \\
\hline Location & Not described & Three hepatic lesions & Segment IV and VII & Posterior segment & Right lobe \\
\hline Maximum size & $6 \times 5 \mathrm{~cm}$ & Not described & $9 \mathrm{~cm}$ & $8.6 \times 5.7 \mathrm{~cm}$ & - \\
\hline Extension & Vascular invasion & Portal vein thrombosis & Portal vein thrombosis & Vertebral metastasis & Lung metastasis \\
\hline Pathological diagnosis & $\begin{array}{l}\text { None (based on the computed } \\
\text { tomography image) }\end{array}$ & $\begin{array}{l}\text { None (based on the computed } \\
\text { tomography image) }\end{array}$ & $\begin{array}{l}\text { Poorly/moderately differentiated } \\
\text { hepatocellular carcinoma }\end{array}$ & $\begin{array}{l}\text { Moderately differentiated } \\
\text { hepatocellular carcinoma }\end{array}$ & $\begin{array}{l}\text { Poorly differentiated hepatocellular } \\
\text { carcinoma }\end{array}$ \\
\hline $\begin{array}{l}\text { Pretreatment before } \\
\text { sorafenib }\end{array}$ & None & Not described & Synchro-level, Vitamin E & TACE $\rightarrow$ PEIT, RFA & $\mathrm{TACE}+\mathrm{RFA} \rightarrow \mathrm{HAIC}(5-\mathrm{FU}+\mathrm{CDDP})$ \\
\hline \multicolumn{6}{|l|}{ Doses of sorafenib (period) } \\
\hline Initial dose & Not described & 800 mg/day (10 days) & 800 mg/day (2 months) & 800 mg/day (2 weeks) & 400 mg/day (1 month) \\
\hline Second dose & $\rightarrow 400$ mg/day (55 months) & $\rightarrow 400$ mg/day (3 months) & $\rightarrow 400$ mg/day (18 months) & $\begin{array}{l}\rightarrow 400 \mathrm{mg} / \mathrm{day} \\
\text { (60 months) }\end{array}$ & $\rightarrow 200$ mg/day (1 months) \\
\hline Third dose & & $\rightarrow 400$ mg/2 days (57 months) & & & $\rightarrow 800$ mg/day (4 months) \\
\hline Fourth dose & & & & & $\rightarrow 400$ mg/day (2 months) \\
\hline Last doses & & & & & $\rightarrow 200 \rightarrow 100 \rightarrow 200$ mg/day (34 months) \\
\hline Total period of sorafenib & 60 months & 62 months & 20 months & 60 months & 42 months \\
\hline $\begin{array}{l}\text { Period of complete } \\
\text { response }\end{array}$ & $<27$ months & 38 months & 28 months & 54 months & 34 months \\
\hline Reported status & Alive & Alive & Alive & Alive & Alive \\
\hline
\end{tabular}


been no signs of recurrence on CT imaging; and his AFP and PIVKA-II levels have also been within the normal limits for the past 34 months.

\section{Discussion}

This patient underwent multidisciplinary therapy including transcatheter arterial chemoembolization, radiofrequency ablation, and continuous hepatic arterial infusion chemotherapy until tumor thrombi were found in the portal vein. We finally initiated sorafenib treatment, and the patient achieved CR soon afterwards and has maintained the CR status for the past 34 months. Based on the clinical course of this patient, the achievement of CR was predominantly attributed to sorafenib therapy. It is extremely rare that a patient with advanced HCC and portal tumor thrombi can achieve long-term $\mathrm{CR}$ without resection.

According to the published literature, there were only four cases of HCC who achieved CR using mainly sorafenib and maintained the status for more than 2 years [8-10]. Table 1 summarizes the patient characteristics of the four reported cases and the present case. All patients were male, and the mean age was 73.4 years old. The background liver disease was hepatitis $C$ in three cases, hepatitis $\mathrm{B}$ in one case, and nothing in one case (present case). The extent of HCC was major vascular invasion in three cases, distant metastasis in one case, and both major vascular invasion and distant metastasis in one case (present case). It is noteworthy that sorafenib was initiated at the recommended dose (800 $\mathrm{mg}$ per day) in three cases, but the dose was soon reduced to $400 \mathrm{mg}$ per day or less in all of them. The final maintenance dose of sorafenib was $400 \mathrm{mg}$ per day in the four reported cases and $200 \mathrm{mg}$ per day in the present case, although the SHARP [4] and Asia-Pacific [5] studies reported that efficacy of sorafenib for advanced HCC was maximally observed at the dose of $800 \mathrm{mg}$ per day.

We also surveyed our single department with regard to sorafenib use for advanced HCC. In 2010, sorafenib became commercially available for advanced HCC in Japan and has been administered to 32 patients with advanced HCC so far in our department. We applied sorafenib at the recommended dose of $800 \mathrm{mg}$ per day in seven patients (cases 1, 6, 20, 27, 29, 31, and 32 in Figure 4), but all of the patients did not tolerate this recommended dose due to side effects or disease progression. Thus, the dose

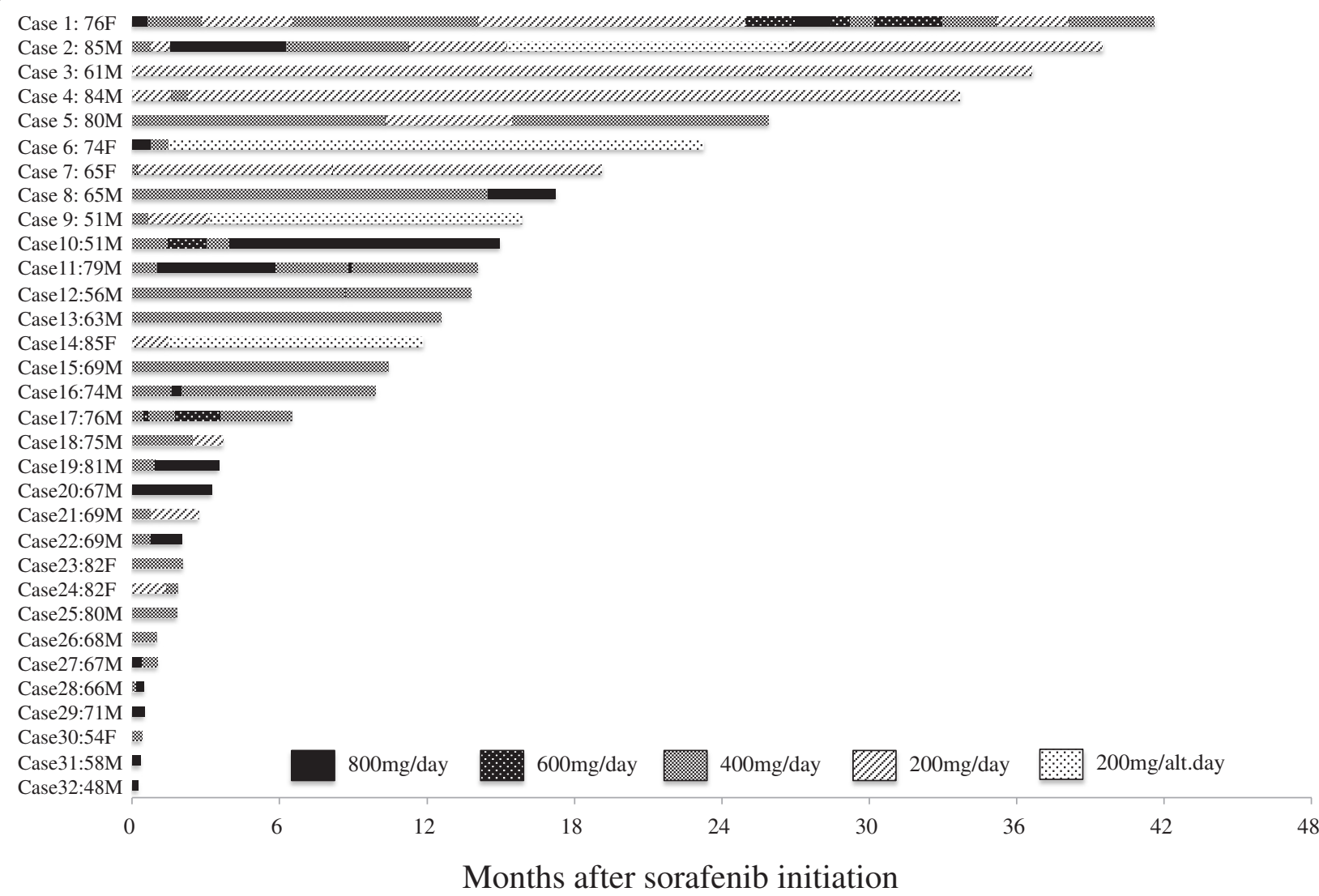

Months after sorafenib initiation

Figure 4 List of cases treated with sorafenib for hepatocellular carcinoma in our department and the doses of sorafenib. Cases are shown in descending order of length of sorafenib treatment. Case 2 represents the present case. Ages shown are at the time of sorafenib initiation. 
had to be reduced in two cases (cases 1 and 6 in Figure 4), and the treatment itself was discontinued in five cases (cases 20, 27, 29, 31, and 32 in Figure 4) within 3 months after initiation of sorafenib. We also found that 14 cases (cases 1 to 14 in Figure 4) took sorafenib for more than 12 months and 7 cases (cases 1 to 7 in Figure 4) took sorafenib for more than 18 months. Most of the long-term recipients of sorafenib were not given the recommended dose of $800 \mathrm{mg}$ per day and had instead reduced doses for most of the treatment period.

\section{Conclusion}

We present here a rare case of advanced HCC, who was initially treated with multidisciplinary therapy including transcatheter arterial chemoembolization, radiofrequency ablation, and continuous hepatic arterial infusion chemotherapy, and achieved long-term CR using reduced doses of sorafenib. Based on our single-center experience of sorafenib use in patients with $\mathrm{HCC}$ and the previously reported cases of long-term CR using sorafenib, it appears that it is important to continue sorafenib for a long time even if the dose is reduced. We hope that this case presentation and literature review serves as a stimulus for further investigation to clarify if using reduced doses of sorafenib for maintenance increase the incidence of CR.

\section{Consent}

Written informed consent was obtained from the patient for the publication of the case report and accompanying images. This case report was written in accordance with the Declaration of Helsinki following approval from our Institutional Review Board (authorization number, 20120443).

\footnotetext{
Abbreviations

HCC: hepatocellular carcinoma; CR: complete response; CT: computed tomography; AFP: alpha-fetoprotein.
}

\section{Competing interests}

The authors declare that they have no competing interests.

\section{Authors' contributions}

MS wrote the paper and conducted the whole treatment. NK and SE analyzed the data in the past cases treated with sorafenib. Ol supervised the writing of the paper especially in the 'Conclusions' section. AU and AT prepared the radiological images and wrote the radiological description. YM and MS analyzed the pathological specimens and wrote the pathological description. MK, YA, TH, and HY prepared the data from the reviewed papers. MT and KA participated in the treatments and supervised the writing of the paper. YK represents our surgical department and supervised the writing of the paper. All authors read and approved the final manuscript.

\section{Author details}

${ }^{1}$ Department of Surgery, School of Medicine, Keio University, 35 Shinanomachi, Shinjuku-ku, Tokyo 160-8582, Japan. ${ }^{2}$ Department of Pathology, School of Medicine, Keio University, 35 Shinanomachi, Shinjuku-ku, Tokyo 160-8582, Japan. ${ }^{3}$ Department of Diagnostic Radiology, School of Medicine, Keio University, 35 Shinanomachi, Shinjuku-ku, Tokyo 160-8582, Japan. ${ }^{4}$ Department of Surgery, Tokyo Medical and Dental University, 1-5-45 Yushima, Bunkyo-ku, Tokyo 113-8519, Japan. ${ }^{5}$ Department of Surgery, Kawasaki Municipal Hospital, 12-1 Shinkawadori, Kawasaki-shi, Kawasaki-ku 210-0013, Japan.
Received: 15 July 2014 Accepted: 23 March 2015

Published online: 09 April 2015

\section{References}

1. Bruix J, Sherman M, Llovet JM, Beaugrand M, Lencioni R, Burroughs AK, et al. Clinical management of hepatocellular carcinoma. Conclusions of the Barcelona-2000 EASL conference. European Association for the Study of the Liver. J Hepatol. 2001;35:421-30.

2. Llovet JM, Burroughs A, Bruix A. Hepatocellular carcinoma. Lancet. 2003:362:1907-17.

3. Bruix J, Sherman M. Management of hepatocellular carcinoma. Hepatology. 2005;42:1208-36.

4. Llovet JM, Ricci S, Mazzaferro V, Hilgard P, Gane E, Blanc JF, et al. Sorafenib in advanced hepatocellular carcinoma. N Engl J Med. 2008;359:378-90.

5. Cheng AL, Kang YK, Chen Z, Tsao CJ, Qin S, Kim JS, et al. Efficacy and safety of sorafenib in patients in the Asia-Pacific region with advanced hepatocellular carcinoma: a phase III randomised, double-blind, placebo-controlled trial. Lancet Oncol. 2009;10:25-34.

6. So BJ, Bekaii-Saab T, Bloomston MA, Patel T. Complete clinical response of metastatic hepatocellular carcinoma to sorafenib in a patient with hemochromatosis: a case report. J Hematol Oncol. 2008;1:18.

7. Shiba S, Okusaka T, Ikeda M, Saito H, Ichida T. Characteristics of 18 patients with hepatocellular carcinoma who obtained a complete response after treatment with sorafenib. Hepatol Res 2014, doi:10.1111/hepr.12297. [Epub ahead of print]

8. Abbadessa G, Rimassa L, Pressiani T, Carrillo-Infante C, Cucchi E, Santoro A. Optimized management of advanced hepatocellular carcinoma: four long-lasting responses to sorafenib. World J Gastroenterol. 2011;17:2450-3.

9. Moroni M, Zanlorenzi L. Complete regression following sorafenib in unresectable, locally advanced hepatocellular carcinoma. Future Oncol. 2013;9:1231-7

10. DU J, Qian X, Liu B. Long-term progression-free survival in a case of hepatocellular carcinoma with vertebral metastasis treated with a reduced dose of sorafenib: case report and review of the literature. Oncol Lett. 2013;5:381-5.

\section{Submit your next manuscript to BioMed Central and take full advantage of:}

- Convenient online submission

- Thorough peer review

- No space constraints or color figure charges

- Immediate publication on acceptance

- Inclusion in PubMed, CAS, Scopus and Google Scholar

- Research which is freely available for redistribution 